\title{
A comparison of insect fruit utilization of Carissa (Carissa edulis Vahl) and Jasmine (Jasminum dichotomum Vahl) in a protected habitat
}

\author{
R. M.Yilangai ${ }^{1}$, A. A. Chaskda $^{1}$, G. S. Mwansat ${ }^{2}$ and O. Akwashiki ${ }^{1}$ \\ ${ }^{1}$ A.P.Leventis Ornithological Research Institute, Laminga, P. O. Box 13404, Jos, North-central Nigeria \\ ${ }^{2}$ Department of Zoology, University of Jos, Jos, North-central Nigeria.
}

\begin{abstract}
Flowering plants and insects dominate the flora and fauna of earth's land surface and interactions between them are dominant elements of the terrestrial ecosystems. This study, determined the insect fruit utilizers of the plants Carissa and Jasmine. The study further compared the two plant species in terms of the diversity of insect fruit utilizers and their frequency of visits. Data was collected in the Amurum Forest Reserve, north central Nigeria, between June and July 2011 through video recordings to identify the insect species and their frequency and duration of visits on the two plants. A total of 322 individual insects spread across 20 species were recorded during the study. C. edulis had the highest diversity and abundance of insect species as compared to J. dichotomum. Thirteen insect species were observed exclusively on C. edulis while 3 insect species were exclusive to J. dichotomum. Insect species diversity and frequency of visits differed significantly between the two study plants in favour of C. edulis. The insect family Formicidae was the most common on both plant species. $99.7 \%$ of individuals were observed foraging on the fruits of the two plants while only one individual insect (i.e. $0.31 \%$ ) exhibited perching behaviour.

Keywords : Insects, Carissa edulis, Jasminum dichotomum, Insect diversity, Frequency of visits
\end{abstract}

\section{Introduction}

Fleshy fruits of tropical forest plants that are consumed by animals occur in different sizes, shapes, colors, and chemical composition [1] and this are exploited in different ways by their animal visitors; for example, during fruit development stage specifically from ripening to dispersal, fruits are exposed to different handling methods by their dispersers this may include swallowing of the whole fruits and seeds or feeding on the nutritive content of the fruit thereby making it unattractive to dispersers. The studies of fruit-insect interaction provide information about seed and fruit predation which is essential in determining the fate of plants in terms of dispersal efficiency and seedling recruitment of such plants in the terrestrial environment. It has been shown from previous studies that interactions between ants and plant fruits/seeds (diaspores) can modify the fate of seeds and affect the distribution and survival of seedlings in plant species that largely depend on vertebrate frugivores for their dispersal [2].

Fruit predation by insects results in reduction in edibility and economic values of fruits and most importantly their dispersal efficiency [3]. In the tropics, little is known about fruit infestation and/or consumption by insects. Scientist have carried out a number of studies on insect frugivory with more emphasis on ant-fruit interaction, but none is of recent years and general insect group has not been covered. Previous studies include: effects of ant-fruit interaction on seeds and seedlings of Guafira opposita; avoidance of insectinfested fruits of Vaccinum ovalifolium; Rainforest ants as secondary dispersers and post dispersal seed predators; [2];[3];[4].

Carissa and Jasmine are widely distributed fruiting plants within and outside the Amurum Forest Reserve due to their observed abundance. Carissa belongs to the family Apocynaceae, the fruits are ovoid in shape, red-black to purplish black in colour, succulent and juicy when fully ripe, with 2-4 flat seeds [1]. While Jasmine belongs to the family Oleaceae, the fruit is a small berry with a single round seed covered by a thin black fleshy layer when ripe [5].

In this study, we examined the fruit-insect interactions of Carissa and Jasmine plants within the Amurum Forest Reserve. The general assumption is that the fruits of these two plants though of similar sizes but different in morphology (e.g. colour) and possibly quality will be utilized by different insect species and at different fruit visit rates in the reserve.

\section{Materials and Methods}

\subsection{Study site}

Amurum Forest Reserve ( $\left.9^{\circ} 53^{\prime} \mathrm{N}, 8^{\circ} 59^{\prime} \mathrm{E}\right)$ located in Laminga village, $15 \mathrm{~km}$ northeast of Jos, Plateau state, North-Central Nigeria. It covers an area of about 300 ha and a mean annual rainfall range of between 
1375-1750 mm per annum with a mean temperature of $10-13{ }^{\circ} \mathrm{C}$. The vegetation is a rocky outcrop in dry scrub savannah with gallery forests and patches of grassland. The most unique species of biological significance are the avifauna population, diverse plant and insect species. The reserve holds about 300 species of birds which includes the nationally endemic Lagonosticta sanquinodorsalis and its brood-parasite Vidua maryae. The common tree species include Khaya senegalensis, Daniella oliveri, Parkia biglobosa, Lophira lanceolata, Ficus $\operatorname{spp}[6]$.

\subsection{Data collection through Video recordings}

Insect observation was done by taking video clips of insect activity on the focal plants using Camcorder (SONY, DCR-SR20; CANON, HR10). A total of 20 individual plants was observed for Carissa and 14 individual plants for Jasmine. Three clusters having greater than five fruits were selected at three different locations per focal plant and recorded for 15 minutes each. Video records obtained from the camcorders were transcribed into the following information: Average insect visit rates per hour and average time spent. Ripe and unripe fruits were counted in each video clip. Insect identification was done using Photographic Atlas of Entomology and Guide to Insect Identification [7] and The Pictoral Encyclopedia of Insects [8].

\subsection{Data analysis}

Data analysis was carried out using R statistical package (2.9.0). The normal Q-Q plot was used to test for normality of response variables.

Insect diversity for each plant species was determined using Shannon Weiner diversity index:

$$
H=\frac{n \log n-\sum f i \log f i}{n}
$$

Where: $\mathrm{fi}=$ number of observations in category $\mathrm{i}, \mathrm{n}=$ sample size

An independent-Sampled t-test was used to test for any significant differences in insect species diversity between Carissa and Jasmine. Kruskal-Wallis test was used to check for difference in mean number of visits among insect orders on Jasmine and Carissa. While Mann-Whitney u test was used to check for difference in number of insect visits between the two plants and difference in time spent foraging by insect species between the two plants. One way ANOVA was used to test for effect of ripe and unripe fruits on number of visits of insect species on the two plants.

\subsection{Insect diversity and visitation}

\section{Results and Discussion}

Twenty (20) insect species belonging to 6 orders were recorded on both Carissa and Jasmine, 17 on Carissa and 7 on Jasmine (Table 1). Four of these were recorded on both plants, while 3 species were exclusive to Jasmine and 14 species were exclusive to Carissa. An independent-Sampled t-test shows a significant difference in insect species diversity between Carissa and Jasmine $(\mathrm{t}=5.34, \mathrm{df}=17.13, \mathrm{p}<0.001$; Fig. 1).

A total of 322 individual insects were recorded from video clips of the two study plants; a total of 35 (representing $10.87 \%$ of 322) were recorded on Jasmine and 287 (i.e. $89.13 \%$ ) on Carissa. Insect Orders on Jasmine, comprise of the Orders; Diptera, Hemiptera, Hymenoptera and Orthoptera with no significant difference in mean number of visits among the insect orders redorded on the plant (Kruskal-Wallis test, $\mathrm{X}^{2}=$ 2.4888, df $=3, \mathrm{p}=0.4773$; Table 2). The insects Orders; Coleoptera, Diptera, Hemiptera, Homoptera and Hymenoptera were recorded on Carissa with significant difference in their mean number of visits on the plant (Kruskal-Wallis test, $\mathrm{X}^{2}=14.1941, \mathrm{df}=6, \mathrm{p}=0.02754$; Table 2). In comparison, mean number of insect visitors was significantly higher on Carissa than Jasmine (Mann-Whitney u test: $\mathrm{W}=255, \mathrm{p}<0.001$; Fig. 2).

2.2. Effect of ripe and unripe fruits on insect visits to plants

The number of ripe and unripe fruits did not have significant effect on number of visit of insect species (One way ANOVA, $\mathrm{F}_{1,225}=0.6483, \mathrm{R}^{2}=-0.001, \mathrm{p}=0.42$ ). Insects visited fruits equally whether ripe or unripe. 2.3. Mean time spent foraging on fruits

The mean time spent foraging by insect species was higher on Carissa (217.95 \pm 22.60 in seconds) than Jasmine (106.18 \pm 32.54 , in seconds) but there was no significant difference (Mann-Whitney u test: $\mathrm{W}=3567, \mathrm{p}$ $=0.4187)$.

Table 1: Checklist of insect species recorded on Carissa and Jasmine 
Insect utilization of Carissa edulis and Jasminum dichotomum fruits in a central Nigerian Forest

\begin{tabular}{|c|c|c|c|c|}
\hline Insect Species & Scientific name & Family name & Order & Identification \\
\hline Alfalfa treehopper & Ceresa taurina & Membracidae & Hemiptera & $\checkmark$ \\
\hline Black carpenter ant & Camponotus pennsylvanicus & Formicidae & Hymenoptera & $\checkmark$ \\
\hline Bug & - & - & Hemiptera & unidentified \\
\hline Cicadas & Tibicen dorsata & Cicadidae & Homoptera & $\checkmark$ \\
\hline Conifer Sawfly & Diprion pini & Diprionidae & Hymenoptera & $\checkmark$ \\
\hline Cuckoo wasp & Chrysura refulgens & Chrysididae & Hymenoptera & $\checkmark$ \\
\hline Damsel Bug & Lasiomerus annulatus & Nabidae & Hemiptera & $\checkmark$ \\
\hline Fire Ants & Solenopsis conjurata & Formicidae & Hymenoptera & $\checkmark$ \\
\hline Gall Wasp & Callirhytis cornigera & Cynipidae & Hymenoptera & $\checkmark$ \\
\hline Green Bug & Schizaphis graminum & Aphidae & Hemiptera & $\checkmark$ \\
\hline Ground Beetle & - & Carabaidae & Coleoptera & unidentified \\
\hline Housefly & Musca domestica & Muscidae & Diptera & $\checkmark$ \\
\hline Ladybird & - & Coccinelidae & Coleoptera & unidentified \\
\hline Lubber Grasshopper & Brachystola magna & Romaleidae & Orthoptera & $\checkmark$ \\
\hline Scarab Beetle & - & Scarabaidae & Coleoptera & unidentified \\
\hline Scuttle Fly & Megalisa scalaris & Phoridae & Diptera & $\checkmark$ \\
\hline Sugar Ant & Camponotus consobrinus & Formicidae & Hymenoptera & $\checkmark$ \\
\hline Tachinid Fly & Hystica abrupta & Tachinidae & Diptera & $\checkmark$ \\
\hline Vinegar Fly & Drosophila repleta & Drosophilidae & Diptera & $\checkmark$ \\
\hline Wasp-mimicking Soldier-fly & Adapsilia illingworthana & Pyrgotidae & Diptera & $\checkmark$ \\
\hline
\end{tabular}

Rows with a tick $(\checkmark)$ implies insect was identified

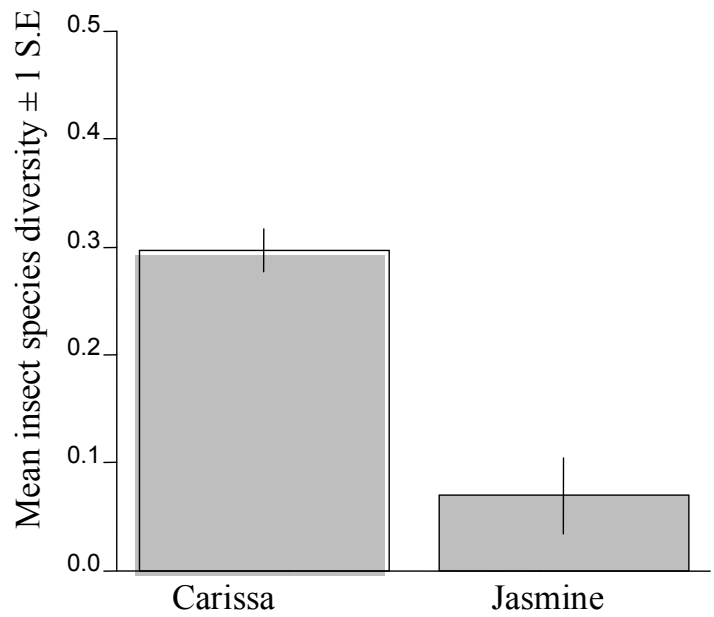

Plant Species

Figure 1: Insect species diversity on Carissa and Jasmine compared

Table 2: Mean number of visits per hour by insect orders on the two study plant species

\begin{tabular}{llll}
\hline S/No & Insect order & \multicolumn{1}{c}{$\begin{array}{c}\text { Carissa }(\mathrm{N}=20) \\
\text { Mean } \pm \text { S.E }\end{array}$} & \multicolumn{1}{c}{$\begin{array}{c}\text { Jasmine }(\mathrm{N}=14) \\
\text { Mean } \pm \text { S.E }\end{array}$} \\
\hline 1 & Coleoptera & $0.27 \pm 0.18$ & - \\
2 & Diptera & $2.33 \pm 0.46$ & $0.48 \pm 0.23$ \\
3 & Hemiptera & $2.40 \pm 0.45$ & $0.29 \pm 0.19$ \\
4 & Homoptera & $3.86 \pm 0.55$ & - \\
5 & Hymenoptera & $10.13 \pm 0.71$ & $2.38 \pm 0.56$ \\
6 & Orthoptera & - & $0.19 \pm 0.22$ \\
\hline
\end{tabular}




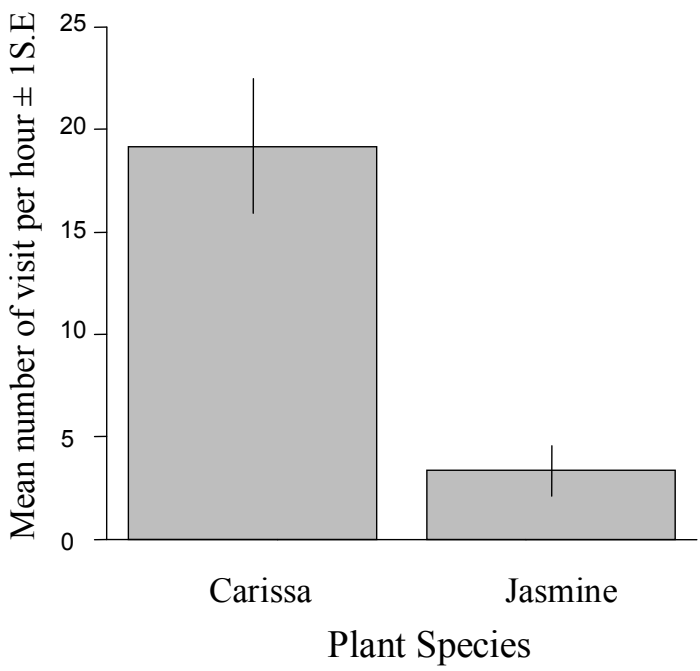

Figure 2: Mean number of hourly visits of insects on Carissa and Jasmine compared

Three insect orders were recorded on both plants; these are diptera, hemiptera and hymenoptera. The order orthoptera was recorded only on Jasmine while coleoptera and homoptera were recorded only on Carissa. The hymenopterans had the highest number of visits among the six orders, $(\mathrm{N}=177) 54.97 \%$. This is probably due to the 'super-abundance' of this group over any terrestrial animals globally as well as their ability to access virtually all types of habitats [9]. The low number of insect visit on Jasmine showed similarity to the result of a study [10] where only lepidopteran larvae was observed to attack Jasmine fruits. Utilization of Carissa fruits by the coleopterans involves biting and chewing. The scarab beetle of the family Scarabaeidae was seen attached to a cluster of ripe fruits for up to 2 days on two different occasions. This observation was only done outside the official observation time, thus it cannot be stated precisely if it was the same individuals that stayed on the fruit for those number of days. The benefit derived from this foraging behaviour of the scarab is that other insect groups like the homopterans (cicadas), hemipterans (damsel bug) and hymenopterans (ants) find it easier to lick up juice from the open fruits. The family Carabidae (the ground beetles) on visit to Carissa fruit fed and left within the period of observation. The hymenopterans and hemipterans were observed on ripe as well as unripe fruits of both Carissa and Jasmine. From observation, ants were seen moving around and licking up the surfaces of ripe and unripe fruits of Jasmine and Carissa. Open ripe fruits of Carissa were more inviting to the ants, cicadas and damsel bugs with movement limited to such fruits and these insects were observed constantly licking up the juice from the fruits. The foraging behaviour of the dipterans involves piercing and sucking of fruit juice. The piercing and sucking behaviour of the dipterans influenced their choice of fruit. Housefly of the family Muscidae was the only dipteran recorded on Jasmine. Carissa fruit being more juicy and sweet smelling was probably a more suitable source of food for the dipterans. The othopterans were only seen perching on Jasmine.

\section{Conclusion}

The two plant species Carissa and Jasmine have been demonstrated in this study as ecologically important food resource for different insect species in the Amurum Forest Reserve. Carissa was clearly the most preferred of the two plants by insects. This preference may be linked to its fruit scent or nutritive value as seen in previous studies. This same plant have also been recorded as an economic fruit tree to the Laminga community [11]. Therefore, the management of this plant in the reserve is of tremendous ecological and economic value.

\section{References}

[1]. R. T. Corlett, Characteristics of vertebrate-dispersed fruits in Hong Kong. Journal of Tropical Ecology, 12 (6), $1996,819-833$.

[2]. L. Passos and P. S. Olivera, Interaction between ants and fruits of Guapira opposita (Nyctaginaceae) in a Brazilian sandy plain rainforest: ant effects on seeds and seedlings, Oecologia 139, 2004, 376-382.

[3]. A. Traveset, M. F. Willson, C. James and Gaither, Jr. Avoidance by birds of insect-infested fruits of Vaccinium ovalifolium, oikos 73(3), 1995, 381-386. 
[4]. D. J. Levey and M. M. Byrne. Complex ant-plant interactions: Rain forest ants as secondary and post-disposal seed predators, Ecology 74(6), 1993, 1082-1812.

[5]. C. Orwa, A. Mutua, R. Kindt, R. Jamnadass and A. Simons, Agroforestry Database: a tree reference and selection guide version 4.0. 2009.

[6]. A. U Ezealor, Critical sites for biodiversity conservation in Nigeria. Nigerian Conservation Foundation: Lagos, Nigeria. (2002)

[7]. J. L. Castner, Photographic Atlas of Entomology and Guide to Insect Identification (Feline Press, 2000)

[8]. V. J. Starnek, The pictoral encyclopedia of insects (The Hamlyn Publishing Group Limited, 1972).

[9]. V. Fourcassie and P.S. Oliveira, Foraging ecology of the giant Amazonian ant Dinoponera gigantea (Hymenoptera, Formicidae, Ponerinae): activity schedule, diet, and spatial foraging patterns. Journal of Natural History, 36, 2211-2227, 2002.

[10]. R.S. Copeland, I.M. White, M. Okumu, P. Machera, R.A. Wharton, Insects Associated with Fruits of the Oleaceae (Asteridae, Lamiales) in Kenya, with Special Reference to the Tephritidae (Diptera). Bishop Museum Bulletin in Entomology 12, 135-164, 2004.

[11]. M.N. Molokwu, Conservation Education and Capacity Building: Rural Participation in Conservation and Production of FuelEfficient Stoves. Rufford small grant foundation Report, 2009. 